JOLANTA KOSZELEW

Bialystok University of Technology, Poland

PIOTR WOLEJSZA

Maritime University of Szczecin, Poland

\title{
DETERMINATION OF THE LAST MOMENT MANOEUVRE FOR COLLISION AVOIDANCE USING STANDARDS FOR SHIPS MANOEUVRABILITY
}

\begin{abstract}
The paper presents a concept of the new algorithm solving Last Moment Manoeuvre problem. Last Moment Manoeuvre means that action taken only by one vessel is not enough to avoid collision. This is why both vessels have to synchronize their manoeuvres to pass each other. The main focus of the proposed solution is concentrated on the procedure defining the best possible manoeuvre for each vessel when avoiding a collision is no longer possible. For simplification, the assumption that the parameters of the vessels involved in the Last Moment Manoeuvre meet Standards for Ships Manoeuvrability set out in the IMO resolution, will be adopted. The algorithm presented in the paper will be implemented and tested in the commercial system.
\end{abstract}

\section{Keywords:}

collision, COLREG, decision support system.

\section{INTRODUCTION}

Human error is the most the important factors causing accidents in maritime transport. According to historical statistics human error was the cause of $80 \%$ of accidents at sea. Therefore development of navigational systems with anti-collision component is very important. Such systems develops the optimum 
route and prevents collisions by automatically detecting potential obstacles static or dynamic.

This paper concerns Last Moment Manoeuvre problem which occurs in the most dangerous situation. The necessity for this type of maneuver is determined by COLREGS. Rule 17 of COLREGs - Action by Stand-on Vessel, paragraph (b) 'When, from any cause, the vessel required to keep her course and speed finds herself so close that collision cannot be avoided by the action of the give-way vessel alone, she shall take such action as will best aid to avoid collision' [COLREGs] describes precisely, when Last Moment Manoeuvres starts.

Last Moment Manoeuvre (LMM in brief) problem is purely described in the literature. There are only few articles on the LMM problem [Koszelew, Wołejsza, 2014; Górski, 2004; Miloh, 1975; Roland, Rohnke, Murphy, 1963]. There are also no public information concerning the implementation of solutions for the LMM which are applied in commercial systems. The reason for this is the high complexity of the parameters which influence the effects of the LMM that is carried by more than one vessel.

The authors of papers concern on LMM often focus only on setting the parameters of encounter situation, which should begin LMM [Youngjun, Key-Pyo, Kyoungsoo, 2013; Krata, Montewka, 2015; Mestl, Tallakstad, Castberg, 2016] or analyze precise cases of encounters (known maneuvering parameters for both ships at risk of collision) causing the necessity of LMM [Górski, 2004].

In [Koszelew, Wołejsza, 2014] authors described the general concept of the new algorithm solving the LMM performed by vessels at open sea. The most difficult part of the solution is the procedure defining the best possible manoeuvre for each vessel when avoiding a collision is no longer possible - the best in terms of minimizing the damage and loss caused by the collision.

Final version of the algorithm will be implemented and tested in the commercial system NAVDEC [navdec.com]. NAVDEC is a multiagent expert system to assist decision-making process in a situation of risk of collision with other vessels. The current version of NAVDEC implements the functionality to support the first four stages of encounter situation from the first stage, in which the distance between own ship and target is so large that a risk of collision is negligible until the fourth stage (Fig. 1), when it is already obvious that the ship, which should give way to a vessel with priority, did not perform anti-collision maneuver and ship with priority has to perform maneuver to avoid collision. Situation on Figure 1 is a screenshot from simulation based on [Bahamas Maritime Authority]. 
North bound vessel is $\mathrm{m} / \mathrm{v}$ 'Baltic Ace', south bound is $\mathrm{m} / \mathrm{v}$ 'Corvus J' (MMSI 259262895). Collision took place in 2012 at North Sea after which Baltic Ace sunk. NAVDEC classifies encounter situation as crossing situation and pointed Baltic Ace as a stand on vessel, which is in line with COLREGs. Despite of it, NAVDEC presents to navigator solutions, how to avoid collision, because vessels are in fourth phase.

Further development of the system is to ensure performance of the last and most dangerous stage of encounter situation - the fifth stage (Fig. 2), in which the action of one vessel only is not enough to avoid a collision. To avoid collisions at this stage the coordinated action of both ships is required. This is the stage of LMM. NAVDEC switches automatically to the fifth stage, when distance between vessels is smaller than $0.5 \mathrm{Nm}$, which is obviously not always correct. The distance heavily depends on vessels parameters and manoeuvring characteristics and could be either smaller or bigger. Above mentioned assumption was based on manoeuvring standards for ships, which says that during executing circulation, the advance could not be bigger than 4.5 length of the vessel. The second assumption is that average length of the vessels is 200 meters. After multiplying both parameters, we receive 900 meter, which is close to $0,5 \mathrm{Nm}$. These are obviously a considerable simplifications.

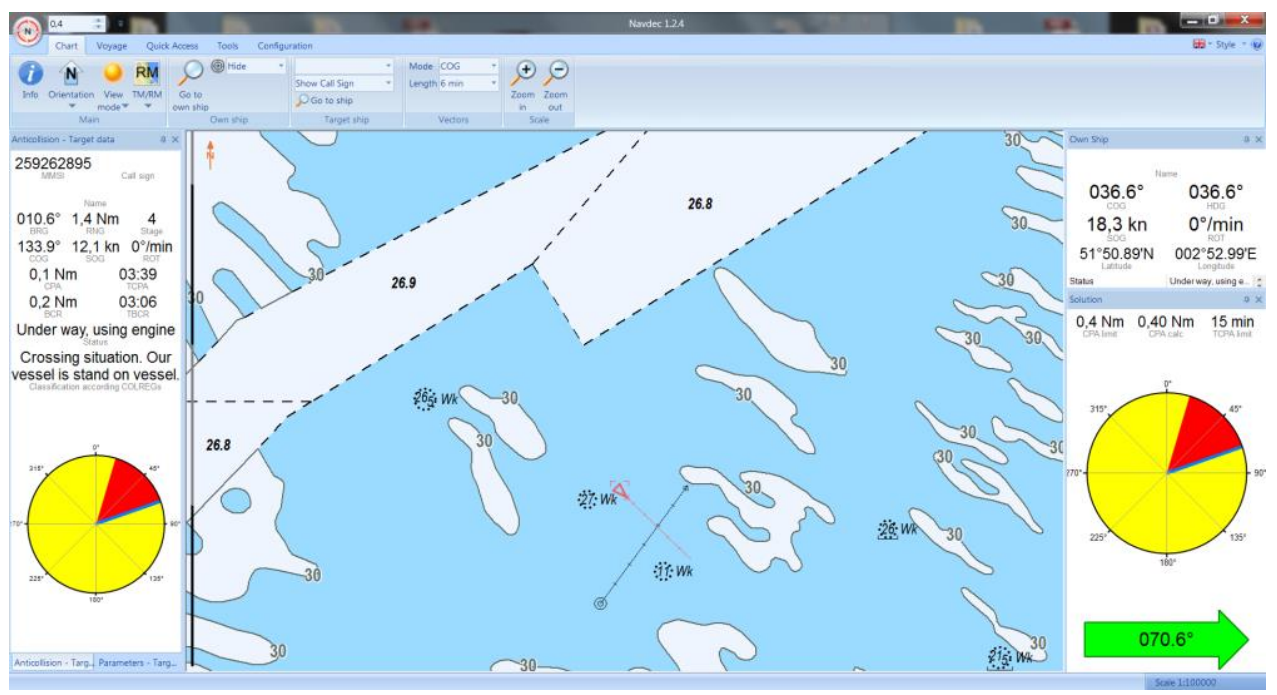

Fig. 1. Collision situation, fourth stage [own study, NAVDEC test situation ] 


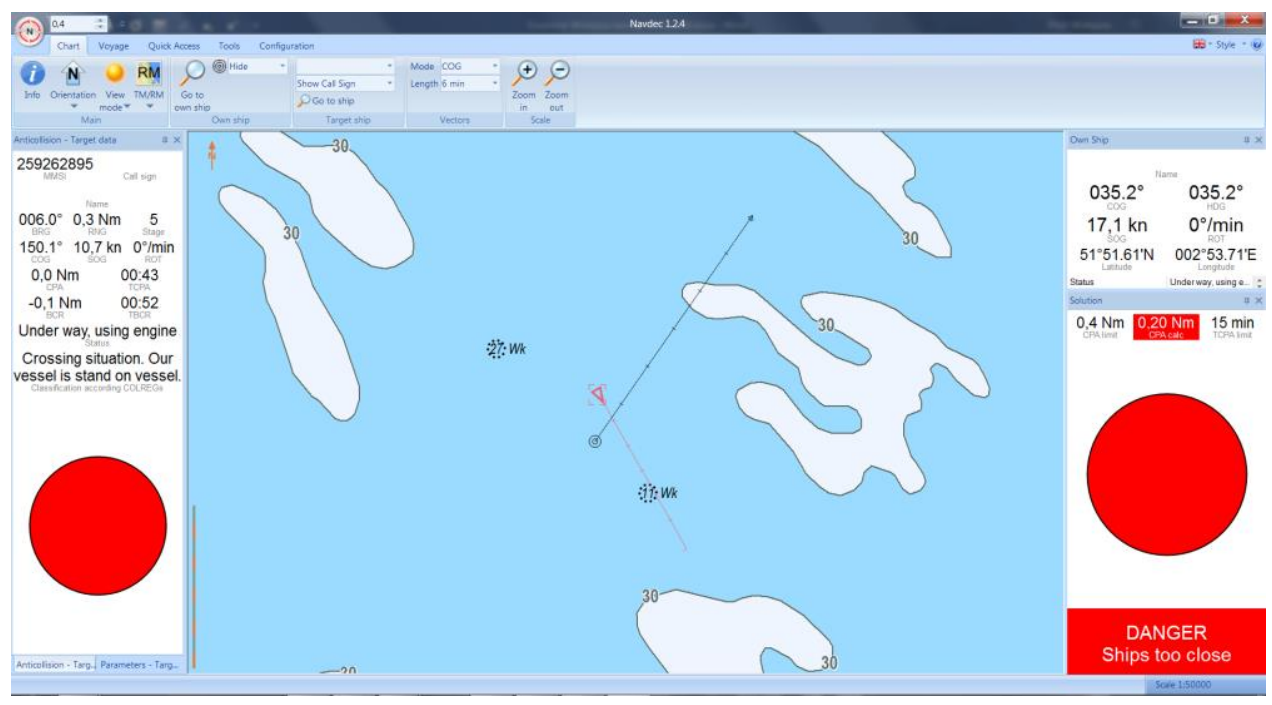

Fig. 2. Collision situation, fifth stage [own study, NAVDEC test situation]

We assume, for simplicity, that in encounter situation only two vessels are involved, both of which are under way using engine, visibility is good and there is a risk of collision. Of course, we assume also that both have installed NAVDEC with fast data exchange protocol. In the current structure of the expert system used in NAVDEC key role plays cooperative agent implemented in the module manager that provides communications between other agents, but only within the system installed on a vessel [Koszelew, Wołejsza, 2014]. Implementation of the solution for LMM problem requires concurrent action of cooperative agents on both ships, which are in the fifth stage of encounter situation.

The paper defines three parts of LMM solution. In addition tasks and procedures that should be executed in these parts. Then Authors describe standards for ship manoeuvrability and present analysis of individual standards in the context of their impact on the LMM performance. In the next part of the paper the algorithm solving second part of LMM is proposed. LMM 2 refers to the situation where both ships must take manoeuvre but avoidance the collision with the proper performance is still possible. The paper concludes with a set of proposals and plans for future development of presented solution. 


\section{USING STANDARDS FOR SHIPS MANOEUVRABILITY IN LMM SOLUTIONS}

The algorithm which solves LMM functionality requires developing and implementation of the following main procedures:

1. LMM 1: the procedure determining the positions $\left(P O_{L M M}, P T_{L M M}\right)$, time $\left(t_{L M M}\right)$ and distance $\left(d_{L M M}\right)$ of the LMM. $P O_{L M M}$ is the position of own $(O)$ and $P T_{L M M}$ of target $(T)$ vessel which are in the fifth stage of encounter situation. After passing this position, it will no longer be possible to passing ships on an assumed minimum distance $d_{\min }$ only by own manoeuvre; $t_{L M M}$ is the exact time at which the positions $P O_{L M M}, P T_{L M M}$ will be achieved by $O$ i $T ; d_{L M M}$ is the distance between $O$ and $T$ in $P O_{L M M}, P T_{L M M}$ at $t_{L M M}$.

2. LMM 2: the procedure defining the best possible manoeuvres for $O$ and $T$ that will avoid collisions and to quickly reach safe positions - positions in which the TCPA < 0; (TCPA - Time to Closest Point of Approach).

3. LMM 3: the procedure defining the best possible manoeuvre for each $O$ and $T$ vessel when avoiding a collision is no longer possible (distance between $O$ and $T$ are still smaller than $d_{\min }$ (despite the implementation of procedures LMM2); the best in terms of minimizing the damage and loss caused by the collision.

Proper execution of LMM1-LMM3 is based on using standards for ships manoeuvrability. In the paper we assume a simplified situation in which the own vessel knows its own physical characteristics and parameters of the maneuvering and the other vessel involved in the collision meets the minimal maneuvering parameters described in Standards for Ships Manoeuvrability set out in the IMO resolution [A137].

According Resolution MSC.137(76) there are four manoeuvering criteria, which should be fulfilled by all vessels longer than $100 \mathrm{~m}$ and chemical tankers and gas carriers regardless their length.

Turning ability

The advance should not exceed 4.5 ship lengths (L) and the tactical diameter should not exceed 5 ship lengths in the turning circle manoeuvre. 
Initial turning ability

With the application of $10^{\circ}$ rudder angle to port/starboard, the ship should not have traveled more than 2.5 ship lengths by the time the heading has changed by $10^{\circ}$ from the original heading.

Yaw-checking and course-keeping abilities

1. The value of the first overshoot angle in the $10^{\circ} / 10^{\circ}$ zig-zag test should not exceed:

$.110^{\circ}$ if $\mathrm{L} / \mathrm{V}$ is less than $10 \mathrm{~s}$,

$.220^{\circ}$ if $\mathrm{LN}$ is $30 \mathrm{~s}$ or more and

$.3(5+1 / 2(\mathrm{~L}, \mathrm{~N}))$ degrees if $\mathrm{L} / \mathrm{V}$ is $10 \mathrm{~s}$ or more, but less than $30 \mathrm{~s}$,

where $\mathrm{L}$ and $\mathrm{V}$ are expressed in $\mathrm{m}$ and $\mathrm{m} / \mathrm{s}$, respectively.

2. The value of the second overshoot angle in the $10^{\circ} / 10^{\circ}$ zig-zag test should not exceed:

$.125^{\circ}$, if $\mathrm{LN}$ is less than $10 \mathrm{~s}$,

$.240^{\circ}$, if $\mathrm{LlV}$ is $30 \mathrm{~s}$ or more and

$.3(17.5+0.75(\mathrm{LN}))^{\circ}$, if $\mathrm{UV}$ is $10 \mathrm{~s}$ or more, but less than $30 \mathrm{~s}$.

3. The value of the first overshoot angle in the $20^{\circ} / 20^{\circ}$ zig-zag test should not exceed $25^{\circ}$.

\section{Stopping ability}

The track reach in the full astern stopping test should not exceed 15 ship lengths. However, this value may be modified by the Administration where ships of large displacement make this criterion impracticable, but should in no case exceed 20 ship lengths [A.137(76)].

Taking into account above listed criteria, we can assume that during executing LMM, still maneuver by course changing, will be much more effective than by the engine. Even medium size vessel of 200 meters needs 3000 meters to stop. Having so much space it is possible to avoid collision even for really huge vessels using only the rudder. So stopping ability can be useful as associated manoeuvre, but not as main one. The main action is connected with turning ability. We are not talking about initial turning ability, because during LMM rather, so called, strong manoeuvres will be executed. The main parameter which will be used during LMM is advance, which according criteria should not exceed 4.5 ship 
lengths. Also tactical diameter of circulation should be taken into account when planning LMM. We can also assume that yaw-checking and course-keeping abilities will not play important role in LMM, because at this point there is no space to change strategy, which was initially developed.

In the next section we will concentrate on concepts of LMM2 and LMM3 procedures and on using standards for ships manoeuvrability in them. We know the exact value of manoeuvrability parameteres for the own ship and we will assume that we will use the standard value of this parameter for the target vessel. The reason for this assumption is that the own ship may not receive on time the information on the exact value of manoeuvrability parameters for the target ship. On the other hand, this assumption results in the adoption by the system the most pessimistic conditions about the maneuvering ability of the target ship which will allow to generate the most secure LMM manoeuvres.

\section{THE ALGORITHM FOR THE LMM 2 PROCEDURE}

In this section we propose the concept of the algorithm solving the main part of the LMM defined in the LMM2 procedure. The algorithms for LMM1 and LMM 3 procedures will be the subject of our next research.

First, we define assumptions and input/output parameters of the LMM 2 and then we present the flowchart of the algorithm.

Assumptions:

- we consider only collision situations on open waters;

- we assume, that there is no wind and no current;

- we can receive information about position and speed of $O$ and $T$ after each $t_{p}$ seconds (in practice $t_{p}$ is max 12 seconds).

Input data:

- $t_{L M M}$ - time at which positions $P O_{L M M}$ and $P T_{L M M}$ will be achieved by $O$ i $T$;

- $t_{p}$ - time interval between AIS messages (for simplification $t_{p}$ is the same for $O$ and $T$ );

- $d_{L M M}$ - distance between $O$ and $T$ in $P O_{L M M}$ and $P T_{L M M}$ at $t_{L M M}$;

- $d_{\min }$ - minimal distance between $O$ and $T$ ensuring the avoidance of collision;

- $P O_{L M M}:\left(x_{O}, y_{O}\right), P T_{L M M}\left(x_{T}, y_{T}\right)$ - positions of $O$ and $T$ in $t_{L M M}$; 
- $V_{L M M}:\left(V_{O}, V_{T}\right)$ - speeds of $O$ and $T$ in $P_{L M M}$;

- $V_{\text {Max }}:\left(\operatorname{Max}_{O} \operatorname{Max}_{T}\right)$ - maximum speeds of $O$ and $T$;

- $c_{L M M}:\left(c_{\mathrm{O}}, c_{T}\right)$ - courses over ground of $O$ and $T$ in $P_{L M M}$;

- $n_{O}$ - exact value of turning ability for $O$;

- $n_{T}$ - pessimistic value of turning ability for $T$ (according IMO).

Output data:

- commands for rudder;

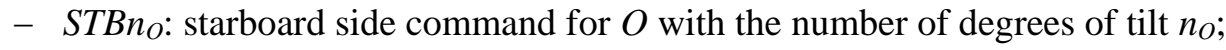

- $S T B n_{T}$ : starboard side command for $T$ with the number of degrees of tilt $n_{T}$;

- commands for engine: $O F A$ full ahead command for $O ; T F A$ - full ahead command for $T$.

At the beginning of the algorithm, we determine the current value of TCPA and check whether the current distance between $O$ and $T$ is large enough that you can still perform a last moment manoeuvre (condition: TCPA $\geq 0 \& d \geq d_{\text {min }}$ ). $d_{\min }$ value is determined as the result of the LMM 1 procedure. If the condition is satisfied then we set all the LMM 2 parameters: commands to the engine and the rudder for both ships. We assume that the safest option of a LMM is: both ships accelerate up to and lining up the rudder to hard to starboard (commands: STBno, $O F A, S T B n_{T}$ and TFA). Such maneuver is not in contradiction with COLREGs rules (altering course to starboard) from one side and enables vessels to change their courses in the fastest way (setting up the telegraph to full ahead) from the other side [Roland, Rohnke, Murphy, 1963].

In the next phase of LMM 2 we determine the trajectories for $O$ and $T$ (Fig. 3), assuming that $O$ and $T$ performed commands generated by the system. Next, after each $t_{p}$ seconds, we check, based on data from the radar and AIS, if each vessel sticks to the designated trajectory (condition: $d \geq d_{\min }$ ). If the condition is not satisfied the LMM 3 procedure is started. If the condition is satisfied and TCPA is less than zero the execution of LMM 2 is finished and system returns to the procedure LMM 1.

It's easy to note that even if the vessel $O$ or $T$ does not perform the recommended manoeuvre in the current step $t$ the algorithm will generate commands: full ahead and maximum port starboard for both ships. Only when distance between vessels will less than $d_{\text {min }}$, system starts performing the LMM 3 procedure (Fig. 5). 


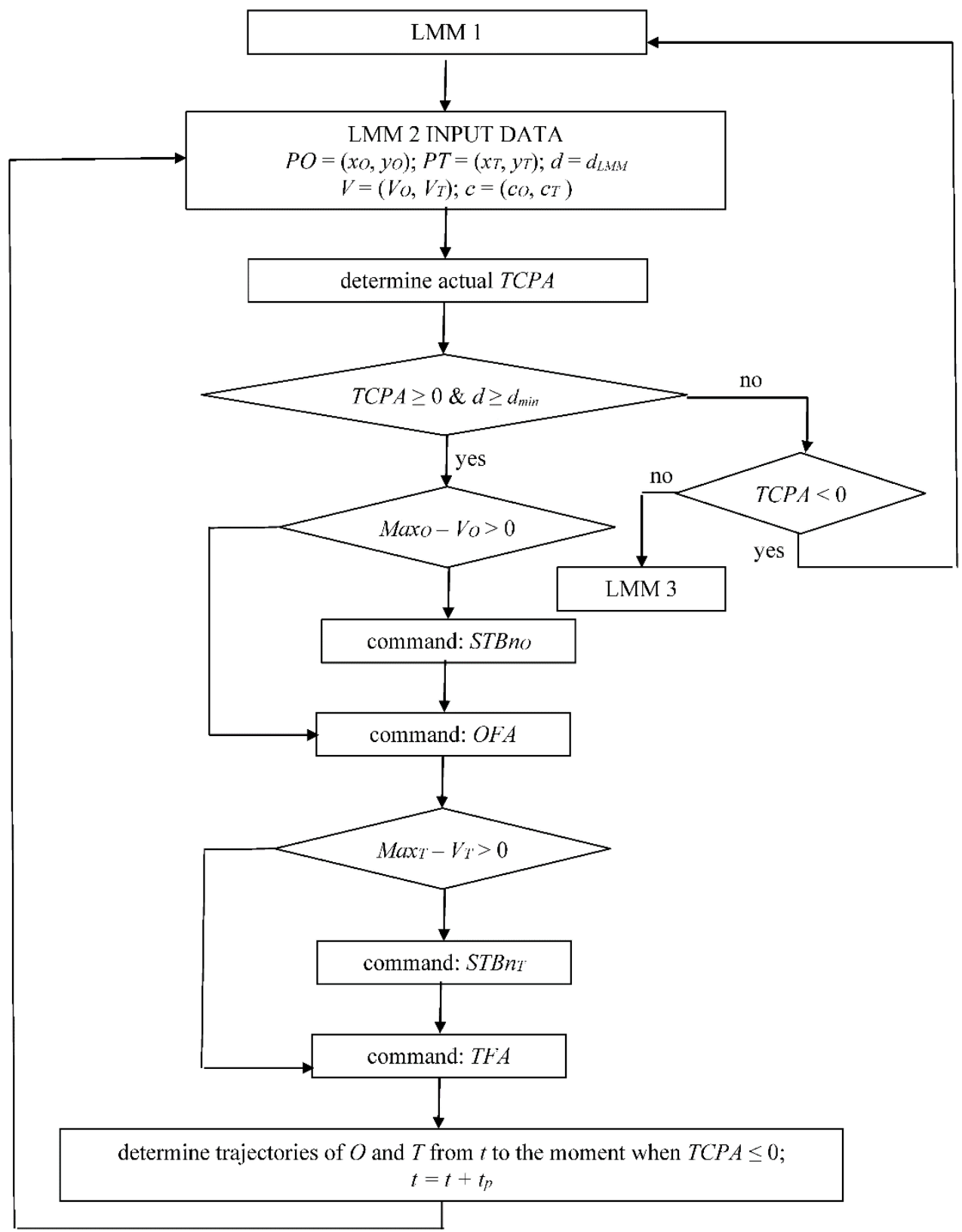

Fig. 3. Flowchart of LMM 2 algorithm 


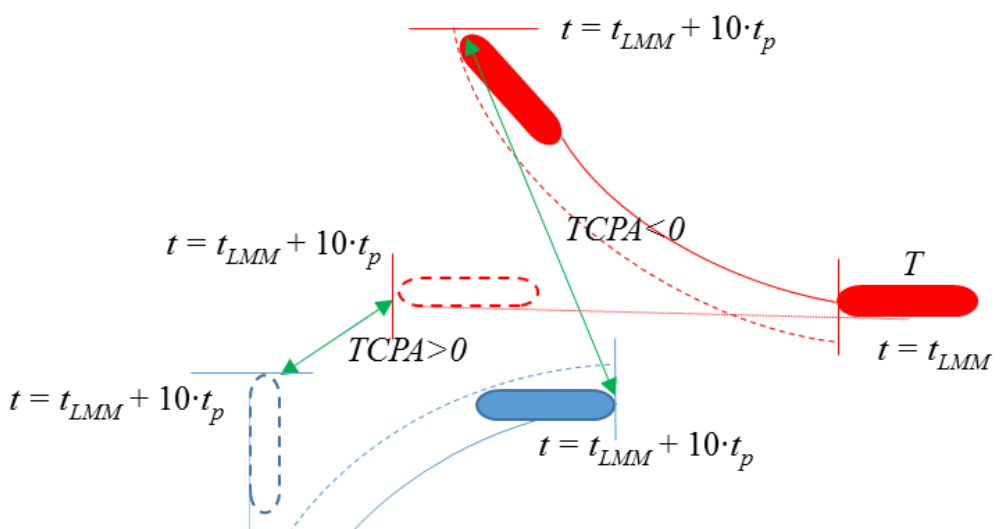

Fig. 4. Example of LMM 2 final solution after ten steps (about 2 minutes) )of the loop; $O$ and $T$ perform manoeuvres and stick to the designated trajectory

$O$

$t=t_{L M M}$
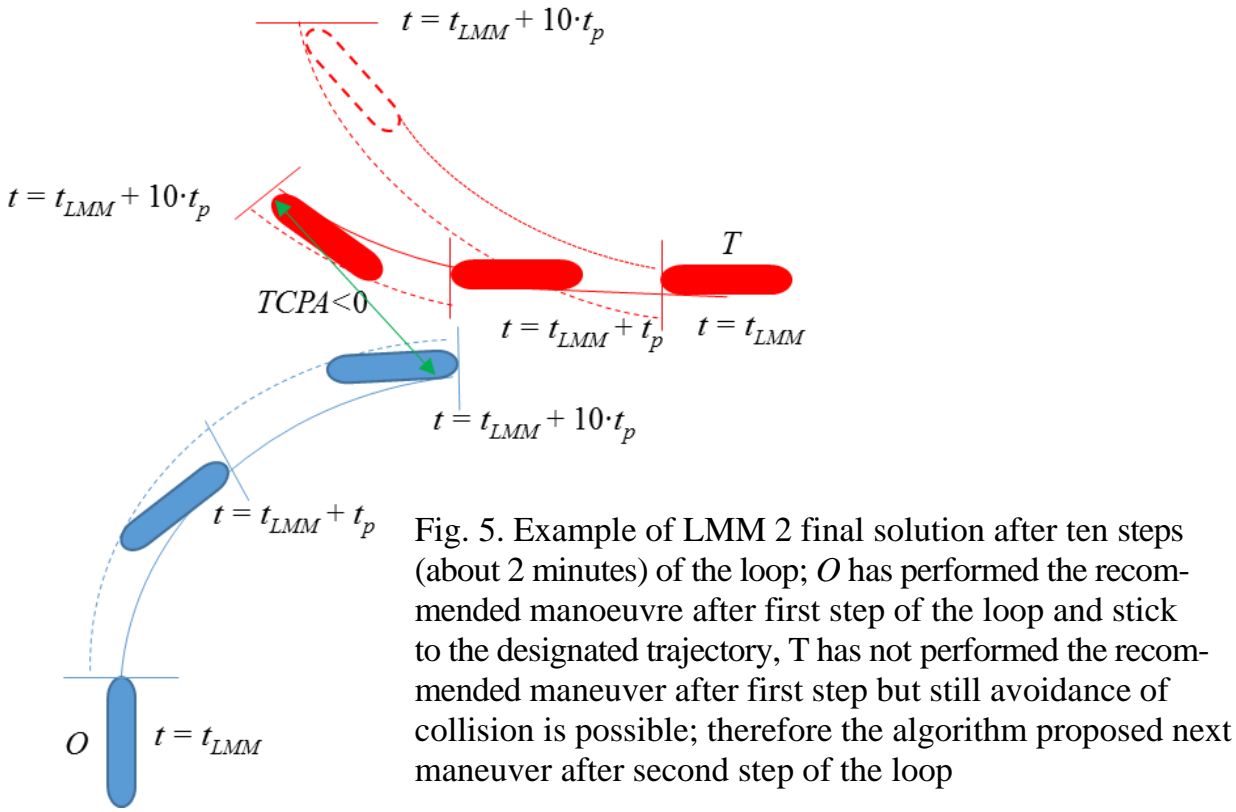


\section{CONCLUSIONS AND FUTURE WORK}

NAVEC system is a system of the future, the future which is inevitable. This is the future of autonomous commercial vessels. Currently, the system correctly classifies all encounter situation but provides anti-collision manoeuvre only by the fourth phase of the meeting. The paper is focused on the last and most dangerous phase of the encounter situation — the Last Moment Manoeuvre, shortly LMM.

The LMM is a key and critical manoeuvre which should be performed by navigators. If vessels are in the fifth phase of the encounter situation the navigators did not take action which was recommended by NAVDEC in the earlier stages of the meeting. This is why it seems reasonable that in this phase navigators shall not control the ship if they did not take any action in earlier phases. The fifth phase of the meeting is critical and there is no time for hesitation in times of stress and panic.

The paper presents the concept of LMM 2 procedure - one of three parts of the algorithm solving LMM. This part is responsible for determining and monitoring LMM while avoiding collisions is still possible. Next research will be concerned on determination of optimal combination of commands for rudder and engine as a result of the last moment manouevre. Determination of such optimal pair of commands require to define and calculate the value of the objective function in the two-criteria optimization algorithm. The goal of the objective function is to minimize the time that elapsing until the condition for a safe distance between ships $\mathrm{O}$ and $\mathrm{T}$ will be fulfilled. Following research will focus on influence of strong manoeuvres e.g. full ahead or full astern on the effectiveness of anti-collision action. For example, full ahead manoeuvre can increase advance but at the same time reduce time required to execute manoeuvre.

Currently, there is no ability to quickly obtain parameters of this ship by the own vessel $O$. Therefore, it seems reasonable to supplement the standard AIS message for manouevre ability. Such addition is possible technologically because there are still free slots in the transmission of AIS. Currently, $T$ maneuvering parameters and commands can be communicated by radio via voice communication by navigators. This type of communication can be confusing, dealing with time and thus ineffective [Bahamas Maritime Authority ]. It is necessary to establish the ontology and communication system between ships that use decision support systems [Pietrzykowski et al., 2014]. 
The next step of research related to LMM is the implementation and testing LMM1 — LMM3 procedures in laboratory and quasi-real environment.

\section{Acknowledgements}

The present study was supported by a grant S/WI/1/2014 from Bialystok University of Technology and founded from the resources for research by Ministry of Science and Higher Education.

\section{REFERENCES}

[1] Bahamas Maritime Authority, Report of the investigation into the loss of m.v 'Baltic Ace' following a collision with m.v 'Corvus J' at the North Hinder Junction Precautionary Area on the 5th December 2012, London 2016.

[2] Górski S., The last minute maneuver, 'European Journal of Navigation', August 2004, Vol. 2, No. 3, pp. 3-5.

[3] IMO Resolution Msc.137(76), Standards for Ships Manoeuvrability.

[4] Krata P., Montewka J., Assessment of a critical area for a give-way ship in a collision encounter, 'The Archives of Transport', 2015, Vol. 34, Issue 2, pp. 51-60.

[5] Koszelew J., Wołejsza P., Last minute manoeuvre as a part of maritime transport logistic systems, 'Logistyka', 2014, No. 4 [CD].

[6] Miloh T., Determination of Critical Maneuvers for Collision Avoidance using the Theory of Differential Games, Technische Universität Hamburg - Harburg, Hamburg 1975.

[7] Mestl T., Tallakstad K. T., Castberg R., Identifying and Analyzing Safety Critical Maneuvers from High Resolution AIS Data, 'International Journal on Marine Navigation and Safety of Sea Transportation', 2016, Vol. 10, No. 1, pp. 69-77, DOI: $10.12716 / 1001.10 .01 .07$.

[8] Pietrzykowski Z., Banaś P., Wołejsza P., Hatłas P., Subontology of the communication in the process automation of the exchange of the information and the negotiation at sea [in Polish], 'Logistyka', 2014, No. 6, pp. 8654-8665.

[9] Roland E., Rohnke O., Murphy C., The manoeuvre of the last safe moment, 'Proceedings of Marchant Marine Council', 1963, Vol. 20, No. 1, pp. 125-162.

[10] Wołejsza P., Navigation Decision Supporting System (NAVDEC) - Testing in Real Condition, 'Annual of Navigation', 2015, Vol. 21, Issue 1, pp. 177-186, DOI: 10.1515/aon-2015-0015.

[11] Youngjun Y., Key-Pyo R., Kyoungsoo A., A method of inferring collision ratio based on maneuverability of own ship under critical collision conditions, 'Int. J. Naval Archit. Ocean Eng.', 2013, 5:188 198, [online], http://dx.doi.org/10.2478/IJNAOE2013-0126 [access 04.10.2017].

[12] www.navdec.eu [access 04.10.2017]. 
Received October 2017

Reviewed December 2017

Published 09.01.2017

\section{JOLANTA KOSZELEW}

Bialystok University of Technology

Wiejska 45A Str., 15-001 Bialystok, Poland

e-mail: j.koszelew@pb.edu.pl

\section{PIOTR WOLEJSZA}

Maritime University of Szczecin

Wały Chrobrego 1-2 Str., 70-500 Szczecin, Poland

e-mail: p.wolejsza@am.szczecin.pl

\section{STRESZCZENIE}

W artykule przedstawiono nowy algorytm rozwiązania, tzw. manewru ostatniej chwili. Pod tym pojęciem autorzy rozumieją manewr, gdy działania podjęte przez tylko jeden statek nie zapewnią uniknięcia kolizji. Dlatego oba statki muszą zsynchronizować swoje manewry, by minąć się bezpiecznie. Istota zaproponowanego rozwiązania sprowadza się do procedury definiującej optymalny manewr dla każdego statku, zapewniając jednocześnie zapobieżenie kolizji. Dla uproszczenia przyjęto założenie, że jednostki spełniają standardy dla sterowności statków ustanowione w rezolucji IMO. Zaproponowany algorytm będzie implementowany i przetestowany w systemie oferowanym komercyjnie. 